Postprint: Indekeu M. L., Feng C., Janssen H., Woloszyn M., 2021. Experimental study on the capillary absorption characteristics of rammed earth. Construction and Building Materials 283122689. https://doi.org/10.1016/j.conbuildmat.2021.122689.

\title{
Experimental study on the capillary absorption characteristics of rammed earth
}

\author{
Margaux L. Indekeu ${ }^{\mathrm{a}, \mathrm{b}, *}$, Chi Feng ${ }^{\mathrm{c}}$, Hans Janssen ${ }^{\mathrm{d}}$, Monika Woloszyn ${ }^{\mathrm{a}}$ \\ ${ }^{a}$ Université Savoie Mont Blanc, CNRS, LOCIE, 73000 Chambéry, France \\ b Université Grenoble Alpes, CNRS, LOCIE, 73000 Chambéry, France \\ c School of Architecture and Urban Planning, Chongqing University, 400045 Chongqing, PR China \\ ${ }^{\text {d }}$ KU Leuven, Department of Civil Engineering, Building Physics and Sustainable Design, 3001 Leuven, \\ Belgium \\ * Corresponding author. E-mail address: margaux.indekeu@live.be.
}

\begin{abstract}
The capillary absorption test is redeveloped for rammed earth building materials. Since these materials liquefy and expand upon contact with water, the standard method must be modified to tackle this material evolution during the test. Firstly, a thin permeable wick and paper are applied as lower sample parts, to counter the liquefaction. It is shown that their influence on the resulting absorption properties is limited. In addition, a confining sealing is utilised against the expansion. It is shown that this confined way of testing offers crucial advantages as a result of the material remaining stable throughout the test.
\end{abstract}

\section{Keywords}

rammed earth; capillary absorption; hygric property; multilayer composite; material evolution; hygromechanical coupling

\section{Highlights}

- The capillary absorption of rammed earth is studied using modified methodologies.

- The wick and paper eliminate liquefaction disturbances during capillary absorption.

- Their hydraulic impact can be corrected by a relatively limited equivalent height.

- The material stability when confined enables a standard hygric characterisation.

- Evolution in the unconfined test induces distortions in the absorption properties.

\section{Introduction}

Historical rammed earth buildings are widely present in France, Europe, as well as in other European countries. To improve the thermal performance of these buildings, they need to be insulated. And to investigate their insulatability via simulation, the hygric material properties are needed. The moisture permeability of these materials is usually only measured in the hygroscopic range, i.e. the (equivalent) vapour permeability [1]. Their 
liquid permeability, on the other hand, is typically predicted via the intrinsic permeability [2] or the capillary absorption coefficient [3-5]. This prediction further remains unverified under the cloak of water being a destructive agent for these constructions. Nevertheless, rammed earth building walls in practice are also exposed to driving rain, and hence the over-hygroscopic properties involved need to be determined as well.

A capillary building material absorbs water actively, which influences the building wall's response e.g. with respect to rain penetration. The basic hygric properties of interest herein are the capillary absorption coefficient and the capillary moisture content, indicating the transfer and the maximum retention of the capillary moisture, respectively. Both properties are determined by means of capillary absorption testing. Besides, this test can serve as a foundation for determining the moisture diffusivity and hence permeability in the high range [6,7].

Findings in the literature [8-10] show that the capillary absorption pattern of rammed earth materials is typically ideal [11], showing a linear relation between the accumulated moisture and the square root of time in the first stage of the capillary absorption process. The capillary absorption coefficient of these materials ranges from about 0.2 to $0.4 \mathrm{~kg} /\left(\mathrm{m}^{2} \mathrm{~s}^{0.5}\right.$ ) (for an open porosity from ca. 0.3 to $0.4 \mathrm{~m}^{3} / \mathrm{m}^{3}$ ), and is generally proportional to the open porosity. Usually, only the capillary absorption coefficient is assessed, or even only the initial rate of suction, while the capillary moisture content remains undiscussed [12].

The rammed earth materials are typically unstable though: they liquefy and expand upon contact with water [2,10,13-19]. Several elementary ways to circumvent this are already found: a wick - a stable porous medium - that is presaturated and hence offers a negligible capillary resistance [20] is used as support between the sample and the water [8], or a confinement is introduced [21, cited in 8]. Notwithstanding, no state-of-the-art consensus on how to deal with the material evolution during the test is reached yet. However, the current typical inconsistency tends to induce problematic uncertainties with respect to the comparability of different results $[2,10,15,22-28]$ and the practical use of the capillary absorption properties [2,6,29-32].

The objective of the present research is hence to find a methodology to consistently implement the capillary absorption test for the determination of the reference capillary absorption properties corresponding to the original state of rammed earth building materials. And the analysis besides aims at clarifying the impact that material evolution can have. The corresponding research question is: 'How to adapt the capillary absorption test method for the determination of the capillary absorption characteristics of rammed earth materials?'.

In Section 2.1, basic information on the rammed earth building materials collected for the characterisation in the lab is gathered. This includes the origin, authenticity and pore structure, homogeneity, bulk density, open porosity, moisture content at $75 \%$ relative humidity, and the capillary absorption coefficient and capillary moisture content determined. Besides, the pore volume distribution and the basic hygric properties of the ceramic brick wick material to be used as the lower part of the composite assembly in the capillary absorption test are presented. Finally, an overview of the samples involved in the research is given. In Section 2.2, the water stability of the materials is discussed, assessed via small water uptake experimenting, X-ray radiography, and mercury intrusion porosimetry. So it is examined to which extent the materials liquefy upon contact with water, remain stable when confined, and expand when unconfined, and in which way this influences the pore structure. On this foundation, the approach for dealing with this material evolution in the capillary absorption test and the strategy for determining the capillary absorption properties is developed. In Section 2.3, the measurement set-up, the experimental procedure, and the data processing for the reference adapted capillary absorption test are explained, as well as modifications to this for the secondary test variant. In Section 3.1, the 
reference part of the test plan is carried into effect and the results are analysed. This brings in feedback that enables to verify that the proper capillary absorption properties are determined with the adapted test method. In Section 3.2, finally, the secondary test variant is used to disclose the impact of material evolution on the capillary absorption properties.

\section{Materials and methodology}

\subsection{Material information}

The target materials for the research are extracted from six traditional rammed earth buildings at different locations in the Auvergne-Rhône-Alpes region, France. For these constructions, typically earth from the site itself was used. For houses 2-6 (H2-6), cohesive samples were used, extracted by means of manual dry core drilling (with maximum sample diameter $7 \mathrm{~cm}$ ) from the inside. For house $1(\mathrm{H} 1)$, no cohesive material is available because it had been crushed [33]; it has therefore been reproduced in the lab by a craftsman via ramming in the form of a block with ca. $7 \mathrm{~cm}$ high layers. The two materials selected, the materials $\mathrm{H} 1$ and $\mathrm{H} 6$, come from this collection of six distinct materials, and they are preferred based on their differences in pore volume distribution, Fig. 1, obtained by mercury intrusion porosimetry [34], as well as for their relative homogeneity. The mercury intrusion porosimetry is performed on samples of $2 \mathrm{~cm}^{3}$. A mercury contact angle of $130^{\circ}[35]$ is assumed. Any ink-bottle (or deformation) effects are assumed negligible for the different materials, which enables interpretation as the proper moisture storage capacity. Air entrapment during wetting is assumed to occur similarly mainly in the coarse pores for the different materials, which leads to their effectively active pore volume distribution that corresponds to the main wetting curve that is cut off at the capillary moisture content [36,37]. Table 1 collects their basic hygric properties. For the H1 material, it is known that its $20 \%$ clay fraction [38] comprises illite and vermiculite [39].

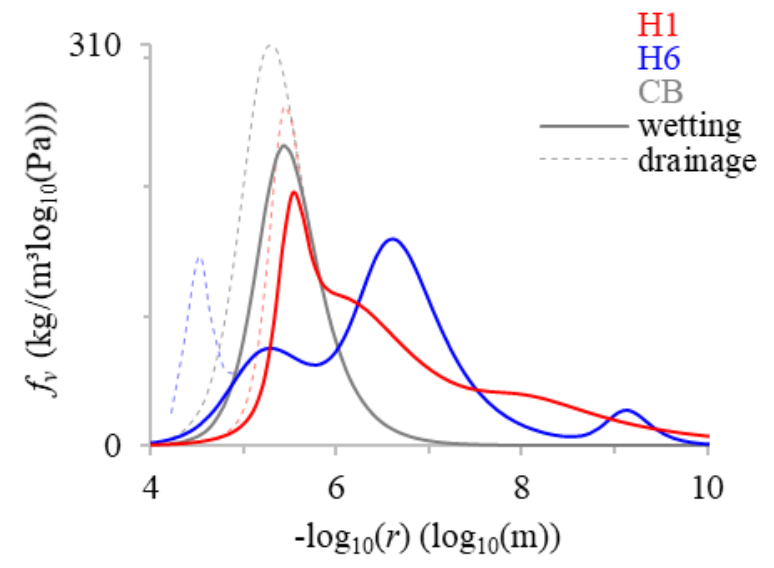

Fig. 1: Pore volume distribution (versus pore radius) of target materials $\mathrm{H} 1$ and $\mathrm{H} 6$ and of wick material CB [6]. 
Table 1: Basic properties of target materials H1 and H6 and of wick material CB [11,40] with material error (\%) and three samples per test used for H1 and H6.

\begin{tabular}{llllll}
\hline & $\begin{array}{l}\text { bulk density } \\
\left(\mathrm{kg} / \mathrm{m}^{3}\right)\end{array}$ & $\begin{array}{l}\text { open porosity } \\
\left(\mathrm{m}^{3} / \mathrm{m}^{3}\right)\end{array}$ & $\begin{array}{l}\text { moisture content } \\
\text { at } 75 \% \mathrm{RH} \\
\left(\mathrm{kg} / \mathrm{m}^{3}\right)\end{array}$ & $\begin{array}{l}\text { capillary absorption } \\
\text { coefficient }\left(\mathrm{kg} /\left(\mathrm{m}^{2} \mathrm{~s}^{0.5}\right)\right)\end{array}$ & $\begin{array}{l}\text { capillary moisture } \\
\text { content }\left(\mathrm{kg} / \mathrm{m}^{3}\right)\end{array}$ \\
\hline $\mathrm{H} 1$ & $1757( \pm 1.9 \%)$ & $0.352( \pm 5.6 \%)$ & $35.0( \pm 0.6 \%)$ & $0.267( \pm 5.5 \%)$ & $284( \pm 3.0 \%)$ \\
H6 & $1708( \pm 2.7 \%)$ & $0.338( \pm 2.4 \%)$ & $18.4( \pm 20.3 \%)$ & $0.190( \pm 21.9 \%)$ & $295( \pm 3.2 \%)^{\mathrm{a}}$ \\
$\mathrm{CB}$ & $1818( \pm 0.9 \%)$ & $0.326( \pm 4.1 \%)$ & $<1.0( \pm 13.5 \%)^{\mathrm{b}}$ & $0.61( \pm 15.2 \%)$ & $210( \pm 4.3 \%)$ \\
\hline
\end{tabular}

${ }^{a}$ Deviation instead of standard deviation because only two results are involved.

b At $85 \%$ RH.

Both target materials are relatively homogenous, as reflected by their material errors (see Table 1) being of similar magnitude as for other building materials [40] (disregarding combinations of different or differences in experimental methods as well as repeatability errors). However, the H1 material has a clear directional heterogeneity in bulk density, of ca. $140 \mathrm{~kg} / \mathrm{m}^{3}$ difference within each layer (densest at the top). This is not captured by its material errors given because representative samples per layer are used. Its samples are taken perpendicular to this gradient for the capillary absorption test for well-defined average results. For H6, any layers are not clearly visible and the sample directions are random. This could additionally contribute to its overall greater inhomogeneity observed, besides its constituting particles showing somewhat greater variations, as well as possible structural features such as asperities and (micro)cracks (along grain boundaries) from past exposure and/or sample sawing.

The bulk density of the materials is determined by means of $70{ }^{\circ} \mathrm{C}$ convection oven drying for the dry mass and immersion in mercury for the volume, since water is destructive [19]. This is performed as part of the mercury intrusion porosimetry test procedure and hence small samples are used.

The open porosity is for operational reasons not measured independently but mainly obtained from the mercury intrusion porosimetry. Because the pores with radii smaller than that corresponding to roughly $70 \%$ relative humidity are beyond the upper limit of the porosimetry pressure range, the open porosity is estimated by the sum of the intruded mercury volume at the pressure corresponding to $75 \%$ relative humidity and the pore volume filled by moisture at the $75 \%$ relative humidity equilibrium moisture content (absorption, assuming hysteresis negligible). The combination of H1's slightly greater open porosity $\left(\Psi_{o}, \mathrm{~m}^{3} / \mathrm{m}^{3}\right)$ and bulk density $\left(\rho_{b u l}, \mathrm{~kg} / \mathrm{m}^{3}\right)$ indicates that the matrix density, estimated via Eq. (1) $[8,9,12,35]$, of H6 is smaller.

$\Psi_{o} \approx \Psi=1-\rho_{\text {bul }} / \rho_{\text {matrix }}$

The equilibrium moisture content at $75 \%$ relative humidity $(\mathrm{RH})$ is determined by means of NaCl-based desiccator testing in absorption at $23.5^{\circ} \mathrm{C}$. This moisture content for $\mathrm{H} 1$ being almost double that of $\mathrm{H} 6$ indicates that the H1 material is more hygroscopic, as can also be noted from the lower part of their respective pore volume distributions, that is determined through additional desiccator testing.

The capillary absorption behaviour of both materials can be expected to be ideal given their pore volume distribution showing one single clear main pore system (the highest peak) that is moreover not coarse enough for gravity to play a role [11]. Because the materials liquefy upon contact with water in a capillary absorption test (Section 2.2), a wick, as well as a paper, is to be introduced as lower sample part for this test. In Appendix, it is shown how the relative hydraulic properties (height and liquid permeability) of the wick and the 
target material play a role in the ability to retrieve the target capillary absorption properties with the adapted (composite) test. So it appears to be of interest that, besides the height of the wick being limited, the pore size of the wick material is larger than that of the target material, resulting in a greater liquid permeability of the wick material (for a rather similar or larger total open porosity of the wick). This corresponds also to a greater capillary absorption coefficient to capillary moisture content ratio of the wick material. And hence, a ceramic brick (CB) material is chosen for the wick: Fig. 1, Table 1. The capillary absorption properties of H1 and H6 in Table 1 result from the reference (confined) test. The capillary absorption tests are performed at ca. $22{ }^{\circ} \mathrm{C}$ (average room and water temperature).

Table 2 and Table 3 show an overview of the samples used for the capillary absorption testing of the H1 and the H6 material respectively, including detailed information such as their sizes: width $(W, \mathrm{~m})$ and thickness $(d, \mathrm{~m})$, or diameter $(D, \mathrm{~m})$ for cylindrical samples, and height $(H, \mathrm{~m})$. The rammed earth samples are typically relatively rough and hence their dimensions (needed separately in the data processing) measured using a caliper are corrected for this as follows. When the caliper $\left(c_{c a l}\right)$ bulk density of a sample is similar to that of other samples of the same material and size, its correction factor $(\delta, \mathrm{m})$ as determined by Eq. (2) is applied, assigning the material bulk density to the sample. Otherwise, the average typical correction factor for the concerned material is applied, allowing the sample's aberrant bulk density. This correction factor typically amounts to ca. $0.00033 \mathrm{~m}$ for $\mathrm{H} 1$ and ca. $-0.00084 \mathrm{~m}$ for H6.

$\left(W_{c a l}+\delta\right)\left(d_{c a l}+\delta\right)\left(H_{c a l}+\delta\right)=W_{c a l} d_{c a l} H_{c a l} \rho_{b u l, c a l} / \rho_{b u l}=W d H=A H$

Table 2: H1 material overview capillary absorption test samples.

\begin{tabular}{llll|llll|ll:}
\hline H1 & \multicolumn{3}{c}{ confined } & \multicolumn{3}{c|}{ unconfined } & \multicolumn{2}{c}{ weathered } \\
sample (S) name & - & - & - & $\mathrm{S} 1$ & $\mathrm{~S} 2$ & $\mathrm{~S} 3$ & $\mathrm{~S} 4$ & $\mathrm{~S} 2$ & $\mathrm{~S} 4$ \\
\hline (initial) state & original & orig. & orig. & orig. & orig. & orig. & orig. & wea. & wea. \\
confinement & yes & yes & yes & no & no & no & no & yes & yes \\
$H(\mathrm{~cm})$ & 8.6 & 9.3 & 2.2 & 9.1 & 9.2 & 3.0 & 2.2 & 9.2 & 2.2 \\
$W$ or $D(\mathrm{~cm})$ & $7.0(D)$ & 6.6 & 6.3 & $7.0(D)$ & 6.6 & $6.9(D)$ & 6.4 & 6.7 & 6.6 \\
$d(\mathrm{~cm})$ & - & 1.4 & 1.4 & - & 1.5 & - & 1.4 & 1.5 & 1.5 \\
$H_{\text {wick }}(\mathrm{cm})$ & 1 & 1 & 0.3 & 1 & 1 & 1 & 1 & 1 & 0.3 \\
paper type & blotting & blot. & filter & blotting & blot. & filter & filter & blot. & filter \\
vapour sealing & yes & yes & yes & yes & yes & no & no & yes & yes \\
measur. method & lab & X-ray & lab & lab & X-ray & metric & metric & X-ray & lab \\
\hline
\end{tabular}

Table 3: H6 material overview capillary absorption test samples.

\begin{tabular}{llll}
\hline H6 & \multicolumn{3}{c}{ confined } \\
\hline (initial) state & original & original & original \\
confinement & yes & yes & yes \\
$H(\mathrm{~cm})$ & 6.0 & 6.2 & 2.2 \\
$W(\mathrm{~cm})$ & 6.4 & 6.4 & 6.4 \\
$d(\mathrm{~cm})$ & 1.4 & 1.5 & 1.4 \\
$H_{\text {wick }}(\mathrm{cm})$ & 1 & 1 & 0.3 \\
paper type & filter & filter & filter \\
vapour sealing & yes & yes & yes \\
measurement method & lab & X-ray & lab \\
\hline
\end{tabular}




\subsection{Adapted test approach and strategy development}

As a starting point, simplified regular capillary absorption tests using small samples lead to the affirmative observation that the rammed earth materials liquefy upon contact with water, as shown in Fig. 2 (a) for H1. This decomposition is a result of the material being soaked through with water, whereby the cohesion of the clay particles that form the natural binder is lost.

(a)

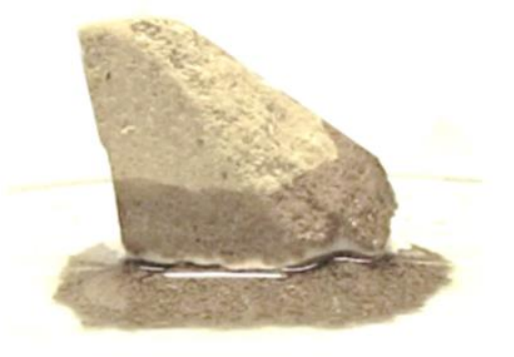

$\mathrm{H} 1$

(b)

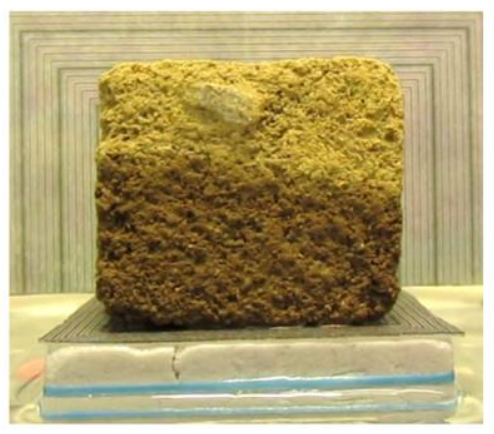

H6

(c)

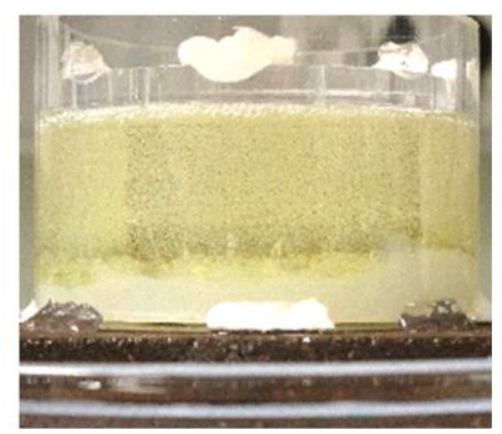

$\mathrm{H} 1{ }^{\prime}$

Fig. 2: (a) Direct, (b) unconfined, and (c) confined small water uptake test.

To avoid this liquefaction, as well as touching impact, a wick and a filter paper layer are introduced such as shown in Fig. 2 (b) with the H6 material. The fibrous paper at the interface moreover enhances the hydraulic contact. Supported by this wick and paper, the second type of small water uptake test is performed to evaluate the expansiveness of a few initially dry ca. $3.1 \times 2.1 \times 2.5 \mathrm{~cm}^{3}$ (width x thickness x height) samples. For this, a camera is used to monitor and graphically assess the uptake and swelling process. Resultantly, it is observed that the one-dimensional horizontal free swelling strain at unconfined capillary saturation (estimated) amounts to a mere $0.5 \%$ for $\mathrm{H} 6$ and as much as $6.5 \%$ for $\mathrm{H} 1$. For comparison, strain values for other rammed earth materials amount to e.g. 1.5\% (after confined saturation and dismantling) [15], 3\% (upon semi-confined saturation) [10], and $4 \%$ for the $\mathrm{H} 2$ material of the collection in the present study. This expansion can, as for 
other porous building materials such as concrete and rocks, be explained by the decrease in suction with increasing moisture content (cf. the effective stress concept) [2,15,29,30] and it becomes additionally pronounced for rammed earth materials by their vulnerable cohesive nature as well as the swelling of clay minerals taking up water molecules [18,28,41,42]. On the basis of the H1 process monitoring, it is clearly observed that the swelling lags behind the moisture front and that the greatest swelling movement occurs after the moment that the moisture front reaches the sample top, which can be explained by the sample acting mechanically as a whole $[29,43]$. Just before the moisture front reaches the sample top, the horizontal strain amounts to ca. $1.5 \%$ for $\mathrm{H} 1$, and just after that but still before the swelling boom, it amounts to ca. $3 \%$. The vertical strain is greater than the horizontal during the first stage (a less restrained deformation takes place) and somewhat smaller in the end (where it amounts to $0 \%$ for $\mathrm{H} 6$ and $5 \%$ for H1; gravity is at play). In theory, these H1 amounts of strain can have an impact of roughly $8 \%$ on the capillary absorption coefficient and $30 \%$ on the capillary moisture content. The former is obtained using Eq. (3) which results from comparing the LucasWashburn equation with the definition of the capillary absorption coefficient $\left(A_{c}, \mathrm{~kg} /\left(\mathrm{m}^{2} \mathrm{~s}^{0.5}\right)\right)[12,44,45]$; the open porosity $\left(\Psi_{o}, \mathrm{~m}^{3} / \mathrm{m}^{3}\right)$ herein is increased by $8 \%$, which results from Eq. (1) considering $1.5 \%$ strain and assuming that the matrix density and solid mass remain constant for simplicity, and the pore radius $(r, \mathrm{~m})$ is kept constant for simplicity. The latter is obtained considering $6 \%$ strain (the average of the horizontal and the vertical strain cf. above) which results in an increase of $30 \%$ of the open porosity. In practice, however, the extreme conditions of fully unconfined wetting as well as extended capillary absorption are uncommon.

$A_{c} \sim \Psi_{o} \sqrt{r}$

Subsequent to the unconfined small water uptake test, the H1 samples are dried in the oven to evaluate the reversibility of the swelling. Upon this drying, it is found that part of the strain is irreversible (ca. 3\% horizontal and ca. $1.5 \%$ vertical residual strain remains for the small samples), implying that the material structure modifies relative to the original one. Hence, a small sample is sawn from the weathered material for a mercury intrusion porosimetry test to assess the impact on the pore structure (owing to the strongly increased crumbliness, it is not known whether this sample comes exactly from the middle as intended). Fig. 3 shows this mercury intrusion porosimetry result for the $\mathrm{H} 1$ material before (original) and after the unconfined water uptake test and redrying (weathered). It is found that the material becomes more wide-porous in two ways. First, existing pores widen (this must result from the wetting). Second, a new system of coarser pores or cracks is formed (this damage can result from the drying shrinkage [43] or it can be formed during the unconfined absorption [28]). Given that complementary desiccator testing shows that the equilibrium moisture content at $75 \%$ relative humidity is not affected by the weathering, it is found that the open porosity increases by $9 \%$. 


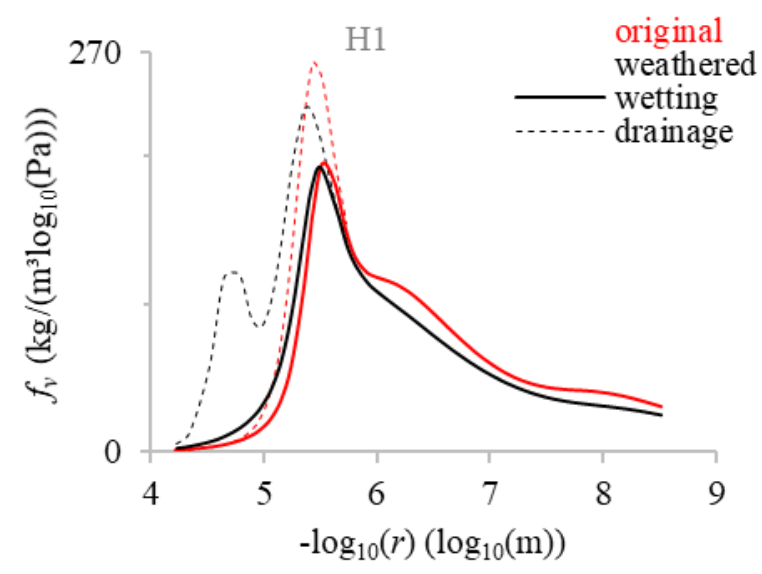

Fig. 3: Pore volume distribution of original and weathered material after unconfined water uptake test for H1 (the capillary moisture content used to cut off the weathered curve results from confined weathered testing).

In a last test setup type, Fig. 2 (c), a confining sealing is additionally applied (besides the wick and paper) to keep the sample mechanically stable (and hence avoid the expansion, with all its consequences) during the water uptake (and redrying) [27], for virgin H1 material. The connection between the confining sealing and the wick should be sufficiently strong to avoid failure by the swelling pressure. Because of this connection being fixed prior to the test, the wick and paper are necessarily initially dry, and hence the setup becomes absorption into a composite sample. In [46,47], it is shown that for a short lower part with a sufficiently high permeability, its impact on the absorption becomes typically negligible after a short amount of time. By way of exception (for operational reasons), a pressed version [48] of H1's material is used for the small confined uptake test: H1', with a bulk density of $1900 \mathrm{~kg} / \mathrm{m}^{3}$. This material variant being even more expansive (10\% horizontal strain observed in the unconfined test), the findings, if successful, are logically transferable to its rammed counterpart, as well as probably to any other (equally or less expansive) regular rammed earth material. Resultantly, first, it is positively verified that the material remains stable during the confined test, implied by the results of capillary absorption tests with X-ray radiography showing a low degree of scatter (cf. set-up Fig. 5, [7,49]). The resulting pore structure is shown in Fig. 4 (a) and is found to be preserved relative to the original one. Additionally, the constancy of the structure and properties is once more confirmed by successfully repeating the capillary absorption test, as shown in Fig. 4 (b): the deviation from the average capillary absorption coefficient e.g. amounts to $\pm 2.3 \%$, which is negligibly small and of similar magnitude as typical repeatability errors from measurements [40]. 


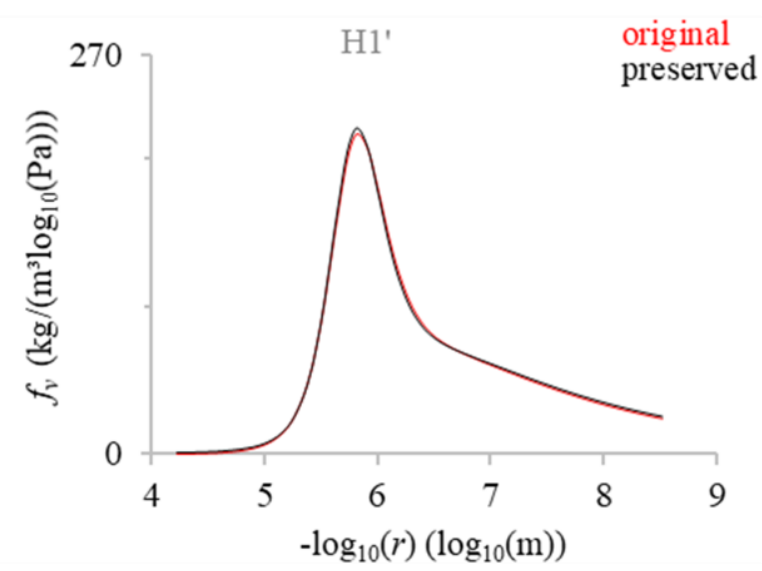

(a)

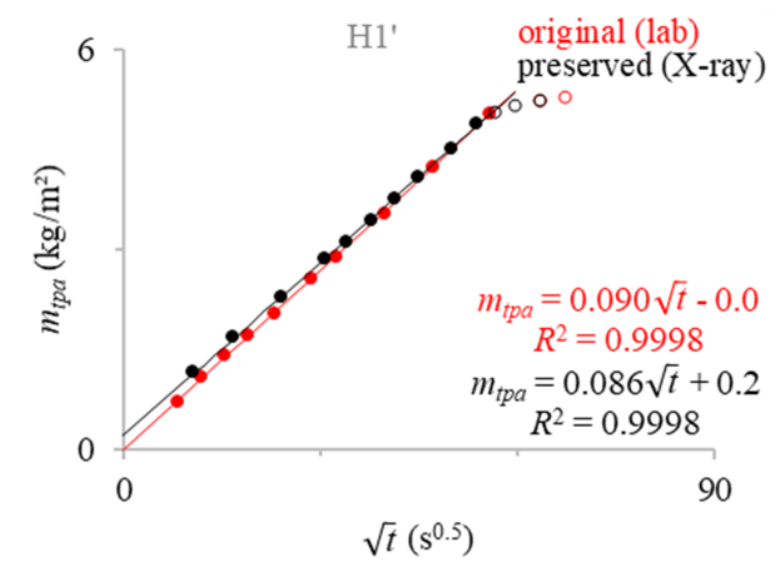

(b)

Fig. 4: (a) Pore volume distribution of original and preserved material after confined water uptake test for H1'

(these curves are not cut off at the capillary moisture content owing to irrelevance for their purpose). (b)

Capillary absorption process from lab and X-ray test including repeatability for confined H1' sample (of $6.4 \mathrm{x}$

$1.4 \times 1.9 \mathrm{~cm}^{3}$ (width $\mathrm{x}$ thickness $\mathrm{x}$ height), with $0.3 \mathrm{~cm}$ high wick of ceramic brick material). This representation

of the accumulated moisture in the top part alone versus the square root of time is explained in Section 2.3.

From this, it follows already that the confined way of testing is chosen to be used for the reference capillary absorption testing (Section 3.1). This also for the barely expanding H6 material because the hydraulic contact can be established more firmly in this way and to possibly reduce the number of samples to be tested as the material certainly remains stable in this way (cf. Table 3). The possible influence of the wick and paper on the capillary absorption is first still explored in advance, experimentally (Section 2.3.1) as well as theoretically (Appendix). After the confined reference tests, the impact of the material evolution through unconfinement on the capillary absorption process is determined and additionally the impact of the weathering is exemplified (Section 3.2). The material evolution impacts are studied only for the clearly expanding H1 material (cf. Table 2). Besides, different sample sizes are used to support the revelation of any hygromechanical effects during the tests (for which in the first place the sample height should be of interest) or for operational reasons (e.g. X-ray versus lab tests can require another sample thickness, and the stock of the material (particularly H6) is limited). 


\subsection{Test setup, procedure, and data processing method}

\subsubsection{Confined test}

As discussed (Section 2.2), the material unstability leads to the test set-up developments of the wick and paper addition (to avoid the liquefaction) and the confining sealing application (to impede the expansion) for the reference test, illustrated in Fig. 5. Because the sample is attached to the wick by the confining sealing, the wick and paper are like the sample applied initially dry, and hence absorption into a composite applies. In [46,47], it is shown that the capillary absorption process into a bilayer composite can be described mainly on the basis of the properties of the second material, as the influence of the properties of the first material becomes negligible as time increases, and this occurs faster for a first material with smaller height and/or larger permeability. The wick is taken no more than $1 \mathrm{~cm}$ high hence, which is the shortest convenient in the sample assembling and positioning, and made of a ceramic brick with a large liquid permeability relative to the target materials, see Fig. 1; the relevant basic properties besides its stability and strength (and homogeneity) are given in Table 1. For the fibrous paper layer providing the hydraulic contact between the sample and the wick, two candidate materials are considered: a $0.16 \mathrm{~mm}$ thick and pliable VWR Grade 415 filter paper and a $1.5 \mathrm{~mm}$ thick and stiffer AllPaper blotting paper. In the sample preparation, a point of particular interest is the maximum flatness of the rammed earth sample and the wick at the interface to form an optimal hydraulic contact with the paper. Furthermore, the cling film (avoiding the penetration of epoxy into the sample) is applied as tight as possible around the sample in order that the cured plastic confinement would effectively minimise the possible expansion afterwards. Besides, the confining sealing is applied with respect to the usual points of interest: the limiting of the evaporation at the lateral and top sides, the allowing of air escape via perforations at the top surface, and the avoiding of the cling film touching the water that would otherwise cause an interstitial water uptake path. After $70{ }^{\circ} \mathrm{C}$ oven drying and recooling to room temperature in a desiccator (with $\mathrm{CaCl}_{2}$ ), the assembly is placed on holders with a negligible contact area at a few millimetres below the water level so that the wick is half-immersed. The water in the tray is deionised with an electrical conductivity of ca. $25 \mu \mathrm{S} / \mathrm{cm}$ and it is ca. $1.5^{\circ} \mathrm{C}$ cooler than the environmental air owing to evaporation.

The experiments are performed in the lab or with X-ray radiography (cf. Tables 2 and 3). The lab test procedure is mainly manual and consists of taking the assembly out of the water at given points in time for weighing. This weighing is preceded by a dab on a moist cloth to remove free water adhered to the bottom surface. The balance used for this weighing has a readability of $0.001 \mathrm{~g}$ up to $1010 \mathrm{~g}$. The time from the moment at which the assembly is taken out of the water to the moment at which it is put back is subtracted for the test time in the data processing; this usually takes ca. $15 \mathrm{~s}$. The test is continued sufficiently long after the moisture front reaches the sample top (e.g. ca. 1.5 times the square root of time at the end of the first stage is sufficient) to enable determining the capillary moisture content. For the X-ray test procedure and radiography data processing, prescriptions $[7,49,50,51]$ are followed. Besides, the full sample width is used to plot the capillary absorption process based on this measurement. 

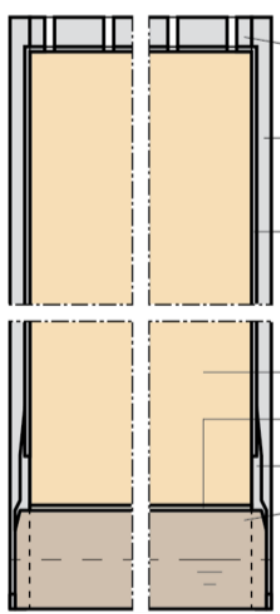

5. Plexiglass lid;

perforations opened after 7 .

7. Epoxy resin confinement, molded using temporary formwork.

4. Cling film, two layers;

perforated along at sample top

after 7.

3. Rammed earth sample.

2. Filter paper.

6. Silicone, applied in several turns.

1. Ceramic brick wick, epoxy-

impregnated part at lateral sides

via painting before assembling.

Fig. 5: Capillary absorption test assembly in confined setup.

The data processing method to obtain the capillary absorption coefficient $\left(A_{c}, \mathrm{~kg} /\left(\mathrm{m}^{2} \mathrm{~s}^{0.5}\right)\right)$ and the capillary moisture content $\left(w_{c a p}, \mathrm{~kg} / \mathrm{m}^{3}\right)$ from the capillary absorption process is demonstrated in Fig. 6 in black, (a) for a standard case and (b) for a composite case. A stable material is used for this to enable comparison with the standard result. In particular, the same ceramic brick (CB) material as that for the wick is used, of which two duplicate samples (S1 and S2) with a height $(H, \mathrm{~m})$ of $12 \mathrm{~cm}$ are tested. First, the capillary absorption process from the standard test using the sample alone is shown (in grey). The coefficient of determination $\left(R^{2},-\right)$ of a linear fitting of the first stage is extremely close to 1 , so the capillary absorption pattern is ideal and the onetangent method [11] is used for the capillary absorption coefficient. Filled markers indicate the data used for this fitting. A zero intercept is found, i.e. the fitted value of the accumulated moisture $\left(m, \mathrm{~kg} / \mathrm{m}^{2}\right)$ in the first stage where the square root of time $(t, \mathrm{~s})$ is zero. The capillary moisture content is determined from the intersection of the first and the second stage fittings, where the second stage can be fitted linearly as well.

Besides this standard, a second configuration is tested: the blue curves in Fig. 6 are the raw measurement data from a composite test wherein the assembly, weighed in one piece, is composed of the ceramic brick sample plus a $1 \mathrm{~cm}$ high wick of the same material, with a fibrous paper at the interface. The two options for this paper are compared: (a) the filter paper and (b) the blotting paper. It is observed that the standard case capillary absorption coefficient is only retrieved after a little while, and that the new intercept is negative. This indicates that the paper offers a hydraulic resistance, implying that the involved configuration acts as a trilayer rather than a bilayer composite. This resistance is smaller for the filter than for the blotting paper, and the first option is therefore preferred (besides, its smaller moisture mass per surface area $\left(A, \mathrm{~m}^{2}\right)$ is more conveniently negligible in general). For the accumulated moisture in the top part alone ( tpa $)$ of the composite, Fig. 6 (b) in black, a constant moisture mass of the wick $\left(M_{\text {wick }}, \mathrm{kg}\right)$ is subtracted, estimated at the average of the vacuum saturation and the capillary moisture content [7] (the paper's moisture mass is neglected). The possible error induced by this preset subtraction weight in the capillary moisture content of the top material hence determined is limited since the wick's height is relatively small. Eq. (4) gives the analytical expression to fit the first stage of this top part alone process that is derived theoretically in Appendix. It shows that if the measurement is sufficiently long to retrieve the proper capillary absorption coefficient (indicated by the persistent ideal behaviour), just a vertical shift is necessary for the standard pattern to coincide with that of the top part alone, or vice versa; the magnitude of this shift corresponds to the hydraulically equivalent ( equ) 
height of the top material for the lower parts. In the ceramic brick application examples, this is already met for times quasi immediately after the water enters the top medium $\left(t_{B}, \mathrm{~s}\right)$. In the case of a top material with a smaller liquid permeability, the impact of the same lower parts tends to be even less pronounced. To conclude, the accumulated moisture in the top part alone versus the square root of time is maintained as standard representation for its clarity, simplicity, and direct usability.

$m_{t p a}=A_{c} \sqrt{t+t_{e q u}-t_{B}}-m_{e q u} \stackrel{\left(\text { for } t \gg t_{e q u}-t_{B}\right)}{\approx} A_{c} \sqrt{t}-m_{e q u}$

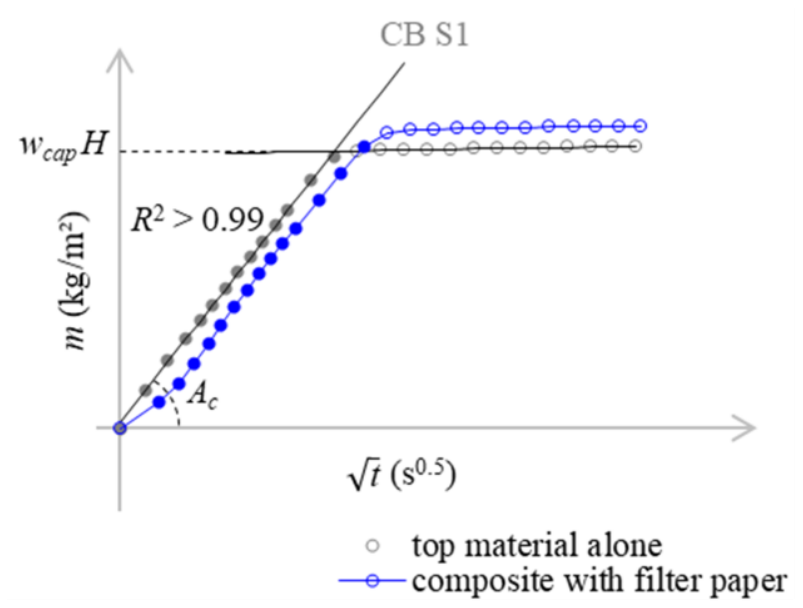

(a)

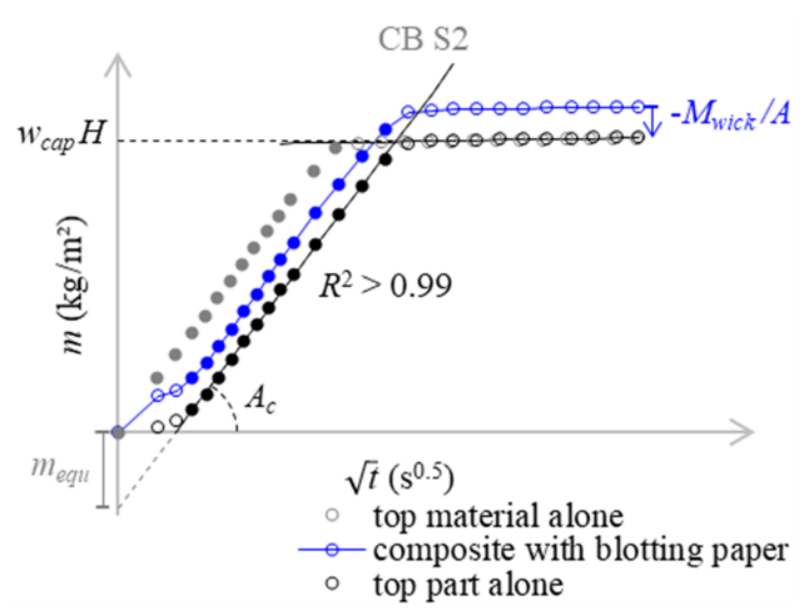

(b)

Fig. 6: Data processing method illustration using ceramic brick capillary absorption test results (a) for standard case and (b) for top part alone of composite case.

\subsubsection{Unconfined test}

The impact of material evolution due to unconfinement on the capillary absorption process is determined for the H1 material only, using samples of four different sizes (Table 2). Like in the confined test, the ceramic brick wick is applied initially dry and $1 \mathrm{~cm}$ high. The surface areas of the wick and the paper are all around the sample ca. $1 \mathrm{~cm}$ larger to support its swelling and to touch only the wick when moving the ensemble. (When drawing the composite moisture accumulation curves, it is advisable to subtract this protruding moisture mass of the wick 
already.) To limit the evaporation via the lateral and top sides, a rather stiff plastic film that rests on the wick is applied (certainly for the tall samples; for the short samples, the impact of this is negligible) loosely enough around the sample to avoid disturbing its swelling by any contact.

During this unconfined test, besides the gravimetric data from weighing (or X-ray radiography), also the moisture front position and the horizontal and vertical swelling are monitored, by filming. When weighing the ensemble, points of interest are to minimise the wiggling (against deformation) and to put it back in the exact same place for the swelling movie. The test is continued sufficiently long to enable determining the unconfined capillary moisture content.

In the gravimetric data processing, the evolutions of the sample dimensions are taken into account as follows. For the capillary absorption coefficient $\left(A_{c}, \mathrm{~kg} /\left(\mathrm{m}^{2} \mathrm{~s}^{0.5}\right)\right)$, the average wet flow surface area is used, which is determined by dividing the wet surface area in front view by the position of the moisture front in the top part alone, and assuming the same strain in the thickness-direction for prismatic samples. For the capillary moisture content $\left(w_{\text {cap }}, \mathrm{kg} / \mathrm{m}^{3}\right)$, the involved swelling in the vertical direction is taken into account as well.

Besides this gravimetric absorption, the metric capillary absorption process is plotted, i.e. the position of the moisture front in the top part alone $\left(x_{\text {front,tpa }}, \mathrm{m}\right)$ versus the square root of time, and the dynamics of the swelling is processed by gathering the horizontal and vertical strain $(\varepsilon, \%)$ in the same plot. The relation $A_{c}=$ $B w_{c a p}$ with the water penetration coefficient $\left(B, \mathrm{~m} / \mathrm{s}^{0.5}\right)$ from the metric process exists if a sharp moisture front is assumed, at least for stable materials, whence it can be seen that this coefficient indicates the transport of the capillary moisture. The horizontal strain is tracked out at three positions along the height $(H, \mathrm{~m})$ of the sample: 1 . $H / 6,2 . H / 2$, and $3.5 H / 6$.

Additionally to the unconfinement impact, the impact of material evolution through weathering consequent to the unconfined test (as well as redrying) on the capillary absorption properties is determined for a tall and a short H1 sample that are both prismatic (Table 2). For this, the weathered material after unconfined absorption and redrying as way of preconditioning is tested in a confined way. The resulting properties are again compared with the reference confined test results.

\section{Results and discussion}

\subsection{Reference confined test}

Fig. 7 shows the capillary absorption process of the three confined samples per rammed earth material (a) for H1 and (b) for H6. Shown are the top part alone data and the first stage fitting. It is observed that a persistent linear pattern is retrieved after some time, supported by the coefficient of determination, which affirmatively indicates that the target materials behave ideally and proves that the impact of the wick plus paper is limited and the proper capillary absorption coefficient is retrieved. The intercept of the corresponding composite curves is usually around zero, but not always is the target behaviour retrieved immediately for the top part alone. For the cylindrical H1 sample (in black), this is most probably explained by the imperfect application of its confining sealing. For the X-ray H6 sample (in red), the random material inhomogeneity could play a part besides the surface roughness at the interface. When more than one slope is retrieved, the last one is retained because it is 
farther away from the lower parts and closer to the final capillary absorption coefficient. Where the target behaviour is retrieved, the top sample behaves as if it were preceded by a certain length of its own material that equals the equivalent height corresponding to the intercept value. This equivalent preceding height is usually smaller than the wick height (but not for the X-ray H6 sample).

Resultantly, the average capillary absorption coefficient amounts to $0.267 \mathrm{~kg} /\left(\mathrm{m}^{2} \mathrm{~s}^{0.5}\right)( \pm 5.5 \%)$ for the $\mathrm{H} 1$ material and $0.190 \mathrm{~kg} /\left(\mathrm{m}^{2} \mathrm{~s}^{0.5}\right)( \pm 21.9 \%)$ for $\mathrm{H} 6$. These property values are within the range expected from the literature and in line with the open porosity trend (Table 1). The average capillary moisture content amounts to $284 \mathrm{~kg} / \mathrm{m}^{3}( \pm 3.0 \%)$ for $\mathrm{H} 1$ and $295 \mathrm{~kg} / \mathrm{m}^{3}( \pm 3.2 \%)$ for $\mathrm{H} 6$, which is relatively similar for both materials. The greater capillary absorption coefficient for $\mathrm{H} 1$ than $\mathrm{H} 6$ in combination with this similar capillary moisture content indicates a greater liquid permeability of $\mathrm{H} 1$, which can be linked to its main pore system having a larger pore radius (Fig. 1).

The capillary absorption coefficient varies more widely than the capillary moisture content between the samples for both materials and in particular for H6. (For H1, the course of the moisture front observed through the discoloration reflects the open porosity gradient within the samples.) No systematic correlations with the different sample dimensions are at play, which confirms once again that the materials remain sufficiently stable during the confined test to deliver the reference capillary absorption properties.

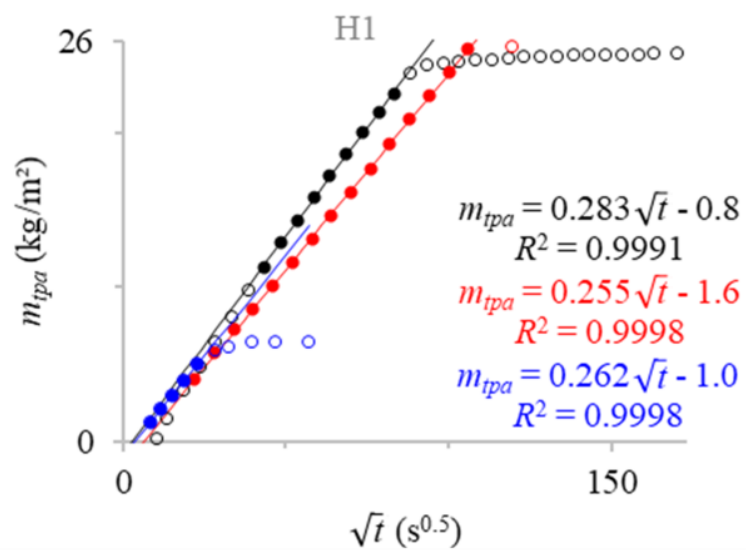

(a)

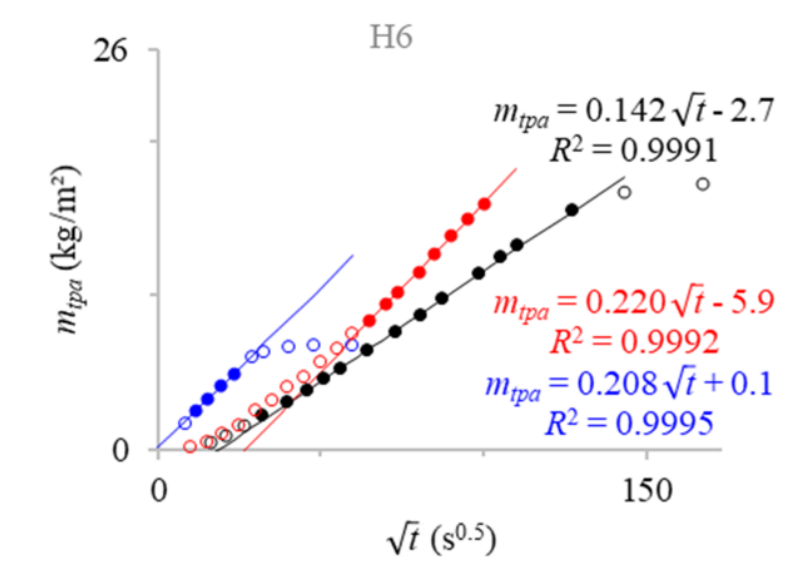

(b)

Fig. 7: Accumulated moisture in rammed earth part alone versus square root of time from reference confined test (a) for $\mathrm{H} 1 \mathrm{samples}$ (ca. $9 \mathrm{~cm}$ or $2.2 \mathrm{~cm} \mathrm{high)} \mathrm{and} \mathrm{(b)} \mathrm{for} \mathrm{H} 6$ samples (ca. $6 \mathrm{~cm}$ or $2.2 \mathrm{~cm} \mathrm{high).}$ 


\subsection{Material evolution impact}

Fig. 8 shows the gravimetric result of the unconfined test for the tall sample S1 of H1 (in black; a reference confined result from Section 3.1 is shown in grey). It is observed that the capillary absorption pattern is ideal, in spite of pore swelling sometimes being suggested as a reason for an irregular behaviour [11,52]. The unconfined way of testing yields a significant capillary absorption coefficient increase of $33 \%$ and capillary moisture content increase of $30 \%$ for this sample relative to the respective average confined results. When the original sample dimensions are not adjusted and kept constant in the data processing, this becomes $37 \%$ and $49 \%$, respectively. The capillary absorption coefficient increases much more than theoretically predicted (Section 2.2), which could be explained by (micro)cracks. The transition from the first to the second stage is smoother unconfined, which can be linked to the swelling. The corresponding moisture front position and strain progress for this sample are shown in Fig. 9 (a).

The resulting capillary absorption properties for the four unconfined H1 samples are shown in Fig. 11 (b). Supported by the metric data available (cf. Fig. 9), it is found that the liquid permeability involved is dependent on the sample height owing to hygromechanical couplings: the smaller the sample height, the less constrained the expansion (both horizontally and vertically, respectively owing to the area moment of inertia of the sample cross section about the bending axis and owing to gravity), and hence the greater the material evolution impact. The capillary absorption coefficient furthermore appears to be dependent on the horizontal sample dimensions as well, which can be linked to the area moment of inertia as well as boundary effects [53]. The unconfined capillary moisture content is found to be independent of the sample height or sizes in general. Since the material evolution impact is systematically enhancing, it is quantified in terms of a deviation from the average confined result, Fig. 11 (a).

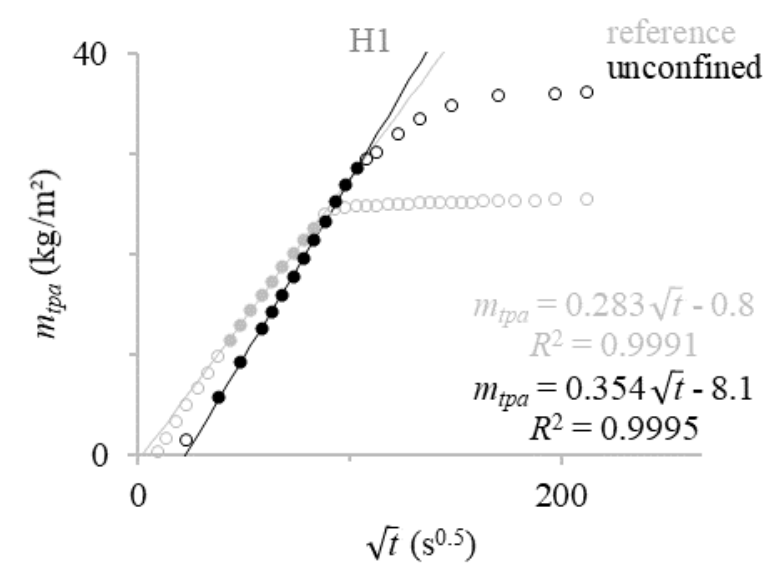

Fig. 8: Capillary absorption process for tall unconfined H1 sample and confined reference. 


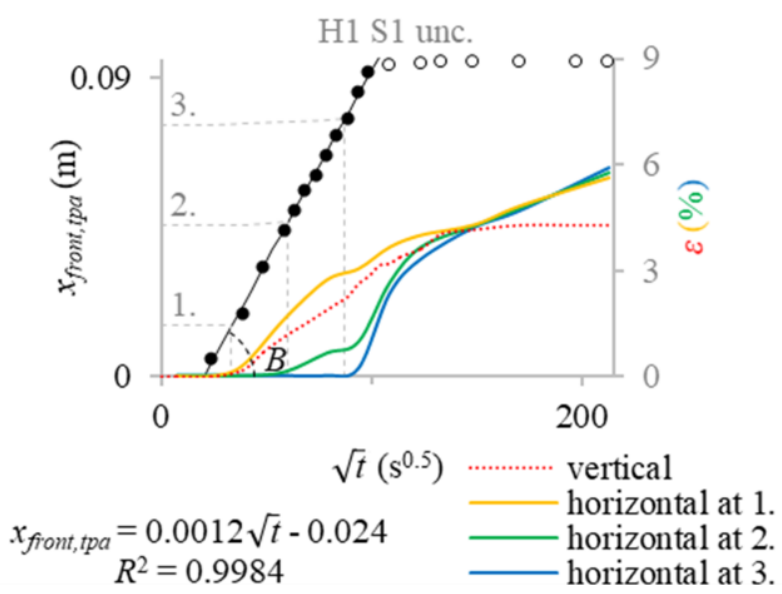

(a)

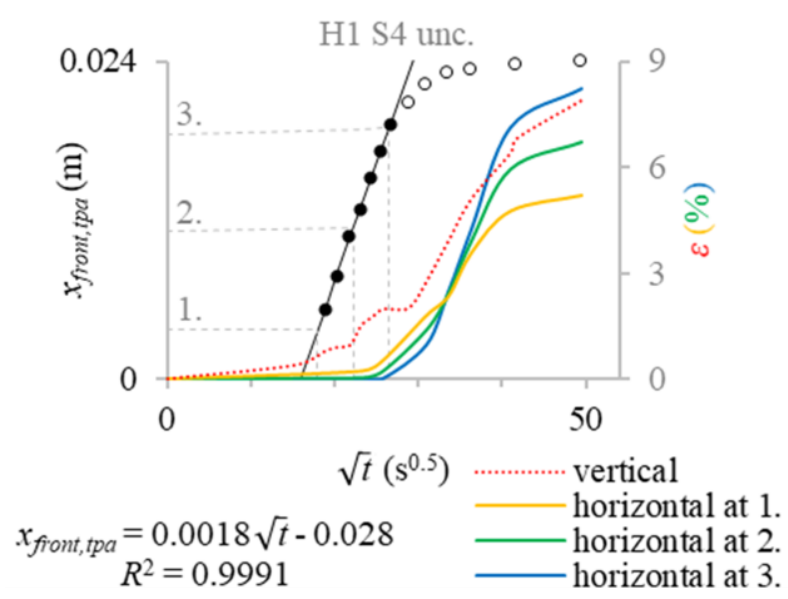

(b)

Fig. 9: Metric capillary absorption and swelling process for (a) tall and (b) short unconfined H1 sample.

The resulting capillary absorption properties for the two weathered samples S2 and S4 of H1 are shown in Fig. 11 (b). As expected based on the pore structure modifications (Fig. 3), the impact of the weathering on the capillary absorption properties is enhancing as well. It is found to be smaller than the unconfinement impact though (additionally supported by metric data). It is presumed that during the confined weathered test, the present cracks tend to close more [54], resulting in a smaller permeability. The difference observed between the capillary absorption coefficient of both samples can be linked to the difference in their degree of weathering (cf. the residual strains in Table 2). The capillary moisture content is again similar for the different sample heights. Fig. 10 shows the result of the weathered confined test for the short sample S4 of H1. For the average weathered capillary absorption coefficient in Fig. 11 (a), only the result of the tall sample S2 is considered to improve the comparability with the unconfinement impact. 


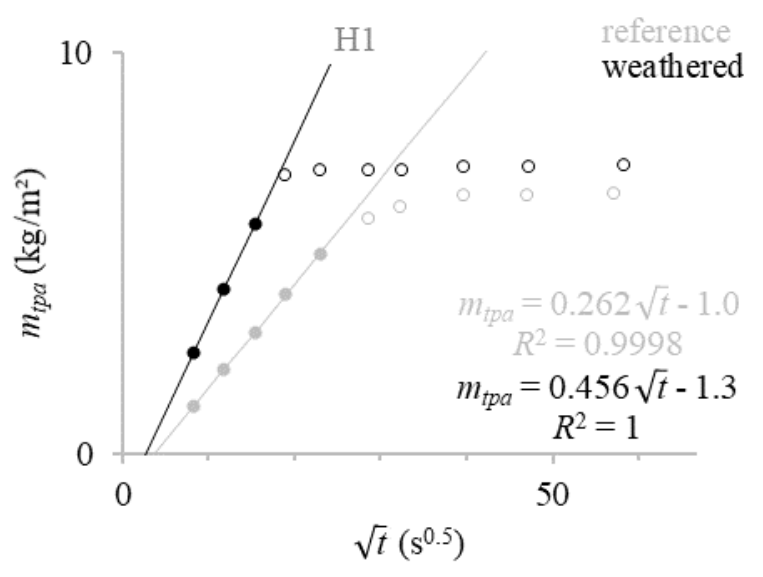

Fig. 10: Capillary absorption process for short weathered H1 sample and confined reference.

Fig. 11 collects all the capillary absorption property results for the H1 material, showing at a glance (a) the impact of material evolution for the average results, with the corresponding deviations from the average confined result and with the error bars representing the deviations of the samples involved, and (b) its inverse relation with the sample sizes for the capillary absorption coefficient. Since the impact of the unconfinement is significant and the properties resulting from the confined test are presumed to be most representative for the hygrothermomechanical state in practice given the wall dimensions, compressive gravitational load, and less extreme climatic boundary conditions, the confined way of testing is conclusively maintained to determine the basic capillary absorption characteristics of interest for the material. As a result of the material remaining stable in the confined test, in contrast to the distortions induced by evolution in the unconfined test, the confined properties are representative for the original state, remain constant, and are sample-size-independent, whereby a consistent standard hygric characterisation is enabled. Besides, it is concluded that more insight into the coupled behaviour and evolution of rammed earth building material walls in practice could be gained by means of numerical simulations based on a hygrothermomechanical theoretical model as well as a more complete material characterisation (including the swelling pressure curve, e.g.). 


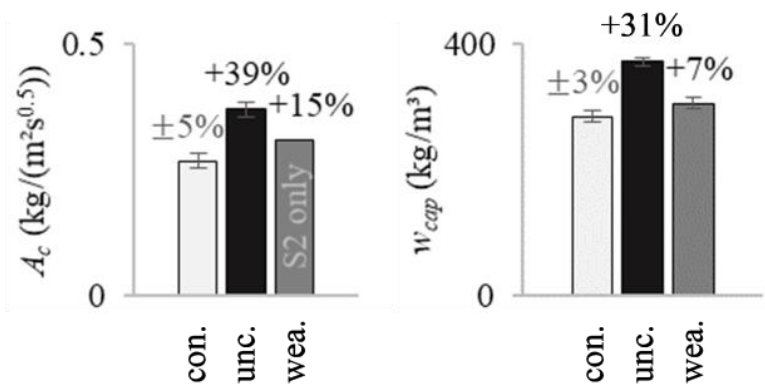

(a)
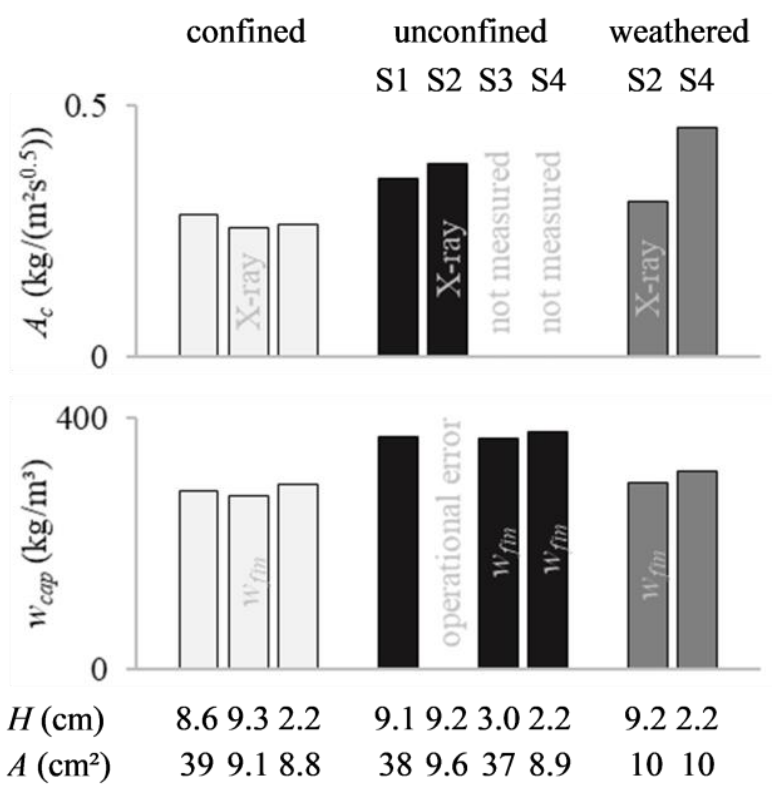

(b)

Fig. 11: H1 overview capillary absorption properties and material evolution impact (a) for average and (b) per sample. The final ( $f_{\text {in }}$ ) second stage moisture content available is used as the capillary moisture content when $\mathrm{X}$-ray tests are not continued sufficiently long to determine the capillary moisture content or for samples that are otherwise only evaluated metrically, both for operational reasons. The X-ray data of the unconfined sample are extremely scattered.

\section{Conclusion}

The capillary absorption properties (capillary absorption coefficient and capillary moisture content) of two different traditional rammed earth building materials are determined by means of capillary absorption testing. Because these materials liquefy and expand upon contact with water, the test method is adapted. In response to the fragmentary state of affairs on this topic before, a conclusive determination method is presented and, besides, the impact of material evolution is clarified.

First of all, a wick and paper are introduced in the test setup as lower sample parts to avoid the rammed earth material liquefaction. The wick is a stable porous (ceramic brick) material that is more permeable than the rammed earth material, and the filter paper enhances the hydraulic contact. These lower parts of the assembly, weighed together with the rammed earth sample in one piece, are applied initially dry and hence maximally thin for a minimal influence on the resulting absorption properties. It is shown that the regular absorption behaviour 
of the rammed earth material is retrieved fast in the process. The estimated saturated moisture mass of the lower parts is simply subtracted. Their hydraulic impact could eventually be corrected by an equivalent height. Additionally, a confining sealing is applied around the sample top and lateral sides and fixed to the wick, to exclude the rammed earth material expansion. It is shown that this confined way of testing is conclusively maintained as the adapted standard method for otherwise expanding rammed earth materials because the rammed earth material remains stable throughout this test, with the following considerable favourable implications. First, the determined properties are representative for the material in its original state. Second, the capillary absorption properties are constant in time and space and therefore also consistent one another, providing a solid basis for the characterisation. Third, the property results are independent of the sample sizes and hence well-defined. And fourth, the method is preservative, so the sample can be reused or the test repeated. As a result, it is determined that the capillary absorption coefficient amounts to $0.267 \mathrm{~kg} /\left(\mathrm{m}^{2} \mathrm{~s}^{0.5}\right)( \pm 5.5 \%)$ for the first target material studied (H1) and to $0.190 \mathrm{~kg} /\left(\mathrm{m}^{2} \mathrm{~s}^{0.5}\right)( \pm 21.9 \%)$ for the second material (H6), and the capillary moisture content to 284 $\mathrm{kg} / \mathrm{m}^{3}( \pm 3.0 \%)$ for the $\mathrm{H} 1$ material and to $295 \mathrm{~kg} / \mathrm{m}^{3}( \pm 3.2 \%)$ for $\mathrm{H} 6$.

Besides, an unconfined test (i.e. still with the wick and paper but without the confining sealing) is performed for the relatively homogenous and expansive $\mathrm{H} 1$ material to demonstrate the impact of the material evolution. This way of testing requires less work in the setup than confined, but it is more demanding in the data processing as the changing sample dimensions are taken into account. The material evolution impact is significant: it results in capillary absorption properties that deviate always positively and mostly ca. ten times more from the average confined result than the reference material errors from inhomogeneity. Moreover, it is dependent on the sample sizes and thereby related to the hygromechanical couplings involved through bending resistance, e.g. The material dried after this unconfined test is weathered relative to the original state, which involves an increased porosity through widened pores as well as cracks.

To conclude, when dealing with the typically unstable rammed earth building materials in future implementations of the capillary absorption test for the determination of their capillary absorption properties, one should pay proper attention to the possible material evolution impact. To realise this, it is recommended to simply use a well-designed wick and paper when necessary, to eliminate disturbances from liquefaction (decomposition as well as touching impact) while minimising any delay in obtaining the target capillary absorption behaviour. Furthermore and especially for clearly expanding rammed earth materials, it is recommended to use a confining sealing to keep the sample mechanically stable and hence exclude distortions in the determined properties. The confined test results are suitable for hygrothermal simulation purposes, where the material structure is inherently assumed to be invariable. Moreover, the confined test method provides a solid basis for the further hygric characterisation in the over-hygroscopic range. In addition to this basic hygric characterisation, hygromechanical behaviour, for example disclosed through unconfined testing, should be explored in the future for the knowledge to gain regarding the hygrothermomechanical performance with respect to the insulatability of rammed earth building walls seen in practice.

\section{Acknowledgements}

The research work presented is realised in the context of the first author's doctoral thesis (in progress) at the Université Savoie Mont Blanc and financed by the Région Auvergne-Rhône-Alpes. Much of the experimental activities have been performed in the facilities of the Building Physics and Sustainable Design section of KU 
Leuven, as a visiting scholar. For the material support, the authors would like to acknowledge ENTPE, dr. ir. Eric Maire, Bruno Pinjon, and Jimmy Van Criekingen. In addition, the authors would like to acknowledge dr. ir. Evy Vereecken for her practical advice with respect to experimental matters.

\section{Appendix Theoretical substantiation}

The capillary absorption into a multilayer composite is dominated by the properties of the last active medium provided that the hydraulic resistance $\left(R_{m}, \mathrm{~m} / \mathrm{s}\right)$ of the lower parts is relatively small and the capillary pressure brought about by the lower parts is almost or at least as high as the capillary moisture content capillary pressure of the upper material (cf. Fig. 1). The theoretical derivation demonstrating this for a trilayer composite (cf. Section 2.3.1) based on a sharp front model is completely analogous as in [11] for a standard case and in [46] for a bilayer $\left({ }_{b i}\right)$ composite, and it is hence not fully developed here. It starts from the conservation of moisture mass formulation for the composite sample, Eq. (A.1): the increase in accumulated moisture $\left(\mathrm{m}, \mathrm{kg} / \mathrm{m}^{2}\right)$ between two times $(t, s)$, Fig. A.1 (a), must be a consequence of the difference between inflow and outflow, Fig. A.1 (b) (the outflow is relatively negligible). The symbols further stand for the capillary moisture content $\left(w_{c a p}, \mathrm{~kg} / \mathrm{m}^{3}\right)$ of the top material $\left({ }_{c}\right)$, the moisture front position $\left(x_{\text {front }}, \mathrm{m}\right)$, the capillary pressure $\left(p_{c}, \mathrm{~Pa}\right)$ at the water contact $\left({ }_{0}\right)$ and at the moisture front $\left({ }_{c r i}\right)$, the height $(H, \mathrm{~m})$ of materials, and the average moisture permeability in the wet zone $\left(k_{m, w e t}, \mathrm{~s}\right)$ per material. The capillary pressure at the moisture front corresponds to the main peak in the pore volume distribution of the concerned material. Provided that this capillary pressure is sufficiently high at the upper junction, the original average moisture permeability in the wet zone of the target top material can be used.

The solution of the differential equation (after solving for the moisture front position) becomes Eq. (A.2) for the moisture accumulation in the assembly. The capillary absorption behaviour with the capillary absorption coefficient $\left(A_{c}, \mathrm{~kg} /\left(\mathrm{m}^{2} \mathrm{~s}^{0.5}\right)\right)$ of the top material is retrieved except that the total time under the square root is corrected for the difference between the actual $\left(t_{B}, \mathrm{~s}\right)$ and the equivalent time at which the moisture front reaches the second junction $\left(t_{e q u}, s\right)$, and the total accumulated moisture is corrected for the difference between the actual and the equivalent moisture mass of the lower parts; where equivalent means written in terms of the properties of material $\mathrm{C}$ by means of the hydraulically equivalent height of the top material for the lower parts. For relatively small heights of the lower parts as well as rather similar or decreasing permeabilities throughout the assembly, the same square root of time behaviour as for the standard case with the top material is retrieved after a relatively short amount of time, from which the proper capillary absorption coefficient can be determined. The retrieval of a persistent ideal pattern (for top materials that behave ideally) is sufficient to prove that this is met. Besides, the actual preceding time under the square root could be estimated as the time at the point of intersection between linear approximations of the process in materials B and C based on the composite curve [46], and the equivalent preceding time as written in the equation which means corresponding to where the fitted value of the accumulated moisture in the top part alone equals zero (cf. Fig. 6 (b)). The accumulated moisture in the lower parts is subtracted to give the accumulated moisture in the top part alone (cf. Eq. (4)), from which the capillary moisture content of the top material can be determined, as well as the equivalent height via the intercept. 


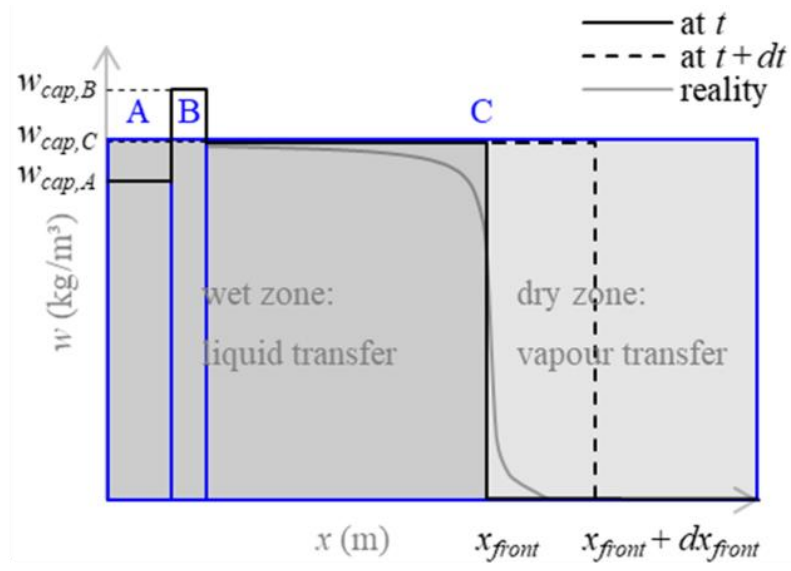

(a)

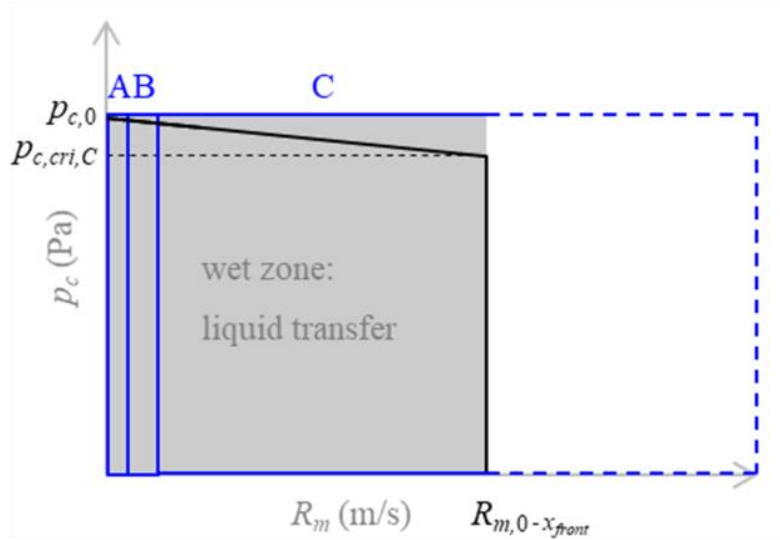

(b)

Fig. A.1: Capillary absorption model for trilayer composite of materials A, B, and C: (a) simplified moisture content profile behaviour and realistic moisture content profile (shown in top part alone) and (b) snapshot of capillary pressure distribution as a function of hydraulic resistance.

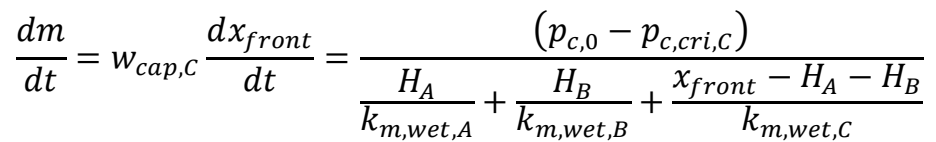


$m$

$=\sqrt{2 k_{m, w e t, C}\left(p_{c, 0}-p_{c, c r i, C}\right) w_{c a p, C}}$

$$
\begin{aligned}
& \sqrt{t+\frac{\left(k_{m, w e t, C}\left(\frac{H_{A}}{k_{m, w e t, A}}+\frac{H_{B}}{k_{m, w e t, B}}\right)\right)^{2} w_{c a p, C}}{2 k_{m, w e t, C}\left(p_{c, 0}-p_{c, c r i, C}\right)}-\frac{\left({H_{B}}^{2}+2 H_{B} \frac{k_{m, w e t, B}}{k_{m, w e t, A}} H_{A}\right) w_{c a p, B}}{2 k_{m, w e t, B}\left(p_{c, 0}-p_{c, c r i, B}\right)}-\frac{H_{A}{ }^{2} w_{c a p, A}}{2 k_{m, w e t, A}\left(p_{c, 0}-p_{c, c r i, A}\right)}} \\
& -w_{c a p, C} k_{m, w e t, C}\left(\frac{H_{A}}{k_{m, w e t, A}}+\frac{H_{B}}{k_{m, w e t, B}}\right)+w_{c a p, A} H_{A}+w_{c a p, B} H_{B} \\
& =A_{c, C} \sqrt{t+\frac{H_{e q u}{ }^{2} w_{c a p, C}}{2 k_{m, w e t, C}\left(p_{c, 0}-p_{c, c r i, C}\right)}-\frac{\left({H_{B}}^{2}+2 H_{B} H_{e q u, b i}\right) w_{c a p, B}}{2 k_{m, w e t, B}\left(p_{c, 0}-p_{c, c r i, B}\right)}-\frac{{H_{A}}^{2} w_{c a p, A}}{2 k_{m, w e t, A}\left(p_{c, 0}-p_{c, c r i, A}\right)}}-w_{c a p, C} H_{e q u} \\
& +w_{c a p, A} H_{A}+w_{c a p, B} H_{B}=A_{c, C} \sqrt{t+\frac{H_{e q u}{ }^{2} w_{c a p}, c^{2}}{A_{c, C}{ }^{2}}-t_{B}}-w_{c a p, C} H_{e q u}+w_{c a p, A} H_{A}+w_{c a p, B} H_{B} \\
& =A_{c, C} \sqrt{t+t_{\text {equ }}-t_{B}}-m_{\text {equ }}+w_{c a p, A} H_{A}+w_{c a p, B} H_{B}
\end{aligned}
$$

\begin{tabular}{|c|c|c|}
\hline symbol & meaning & unit \\
\hline$A$ & surface area & $\mathrm{m}^{2}$ \\
\hline$A_{c}$ & capillary absorption coefficient & $\mathrm{kg} /\left(\mathrm{m}^{2} \mathrm{~s}^{0.5}\right)$ \\
\hline$B$ & water penetration coefficient & $\mathrm{m} / \mathrm{s}^{0.5}$ \\
\hline$D$ & diameter & $\mathrm{m}$ \\
\hline$d$ & thickness & $\mathrm{m}$ \\
\hline$f_{v}$ & pore volume distribution & $\mathrm{kg} /\left(\mathrm{m}^{3} \log _{10}(\mathrm{~Pa})\right)$ \\
\hline$H$ & height & $\mathrm{m}$ \\
\hline$k_{m}$ & moisture permeability & $\mathrm{S}$ \\
\hline$m$ & accumulated moisture & $\mathrm{kg} / \mathrm{m}^{2}$ \\
\hline$M$ & moisture mass & $\mathrm{kg}$ \\
\hline$p_{c}$ & capillary pressure & $\mathrm{Pa}$ \\
\hline$r$ & pore radius & $\mathrm{m}$ \\
\hline$R^{2}$ & coefficient of determination & - \\
\hline$R_{m}$ & hydraulic resistance & $\mathrm{m} / \mathrm{s}$ \\
\hline$t$ & time & $\mathrm{s}$ \\
\hline$w$ & moisture content & $\mathrm{kg} / \mathrm{m}^{3}$ \\
\hline$W$ & width & $\mathrm{m}$ \\
\hline$x$ & position & $\mathrm{m}$ \\
\hline$\delta$ & correction factor & $\mathrm{m}$ \\
\hline$\varepsilon$ & one-dimensional strain & $\mathrm{m} / \mathrm{m}, \%$ \\
\hline$\rho$ & density & $\mathrm{kg} / \mathrm{m}^{3}$ \\
\hline$\Psi$ & total porosity, i.e. including closed pores & $\mathrm{m}^{3} / \mathrm{m}^{3}$ \\
\hline$\Psi_{o}$ & open porosity & $\mathrm{m}^{3} / \mathrm{m}^{3}$ \\
\hline$A$ & of material A, i.e. the first material of a composite sample & \\
\hline$B$ & of material B, i.e. the second material of a composite sample & \\
\hline$b i$ & bilayer & \\
\hline bul & bulk & \\
\hline$C$ & of material C, i.e. the third material of a composite sample & \\
\hline cal & caliper & \\
\hline
\end{tabular}

\section{Nomenclature}




\begin{tabular}{ll}
$\begin{array}{l}\text { cap } \\
\text { cri }\end{array}$ & $\begin{array}{l}\text { capillary } \\
\text { equ }\end{array}$ \\
equivalent \\
fin & final \\
tpa & top part alone \\
0 & at 0 m position, i.e. at the water contact \\
\hline blot. & blotting \\
CB & ceramic brick \\
con. & confined \\
H & house \\
measur. & measurement \\
orig. & original \\
RH & relative humidity \\
S & sample \\
unc. & unconfined \\
wea. & weathered \\
\hline
\end{tabular}

\section{References}

[1] M. Hall, D. Allinson, Analysis of the hygrothermal functional properties of stabilised rammed earth materials, Build. Environ. 44 (2009) 1935-1942. https://doi.org/10.1016/j.buildenv.2009.01.007.

[2] B. François, L. Palazon, P. Gerard, Structural behaviour of unstabilized rammed earth constructions submitted to hygroscopic conditions, Constr. Build. Mater. 155 (2017) 164-175. https://doi.org/10.1016/j.conbuildmat.2017.08.012.

[3] H. Janssen, A discussion of "Analysis of the water absorption test to assess the intrinsic permeability of earthen materials", Constr. Build. Mater. 215 (2019) 1044-1046. https://doi.org/10.1016/j.conbuildmat.2019.05.016.

[4] D. Allinson, M. Hall, Hygrothermal analysis of a stabilised rammed earth test building in the UK, Energy Build. 42 (2010) 845-852. https://doi.org/10.1016/j.enbuild.2009.12.005.

[5] Hygroba cahier $n^{\circ} 0$ : Généralités. Etude de la réhabilitation hygrothermique des parois anciennes. http://www.rehabilitation-bati-ancien.fr/fr/espace-documentaire/hygroba-etude-de-la-rehabilitationhygrothermique-des-parois-anciennes, 2013 (accessed 28 January 2021).

[6] P. Ren, C. Feng, H. Janssen, Hygric properties of porous building materials (V): Comparison of different methods to determine moisture diffusivity, Build. Environ. 164 (2019) 106344. https://doi.org/10.1016/j.buildenv.2019.106344.

[7] J. Carmeliet, H. Hens, S. Roels, O. Adan, H. Brocken, R. Cerny, Z. Pavlik, C. Hall, K. Kumaran, L. Pel, Determination of the liquid water diffusivity from transient moisture transfer experiments, J. Therm. Envelope Build. Sci. 27 (2004) 277-305. https://doi.org/10.1177/1097196304042324.

[8] M. Hall, Y. Djerbib, Moisture ingress in rammed earth: Part 1 - The effect of soil particle-size distribution on the rate of capillary suction, Constr. Build. Mater. 18 (2004) 269-280. https://doi.org/10.1016/j.conbuildmat.2003.11.002.

[9] M. Hall, D. Allinson, Influence of cementitious binder content on moisture transport in stabilised earth materials analysed using 1-dimensional sharp wet front theory, Build. Environ. 44 (2009) 688-693. 
https://doi.org/10.1016/j.buildenv.2008.05.013.

[10] A. Fabbri, L. Soudani, F. McGregor, J. C. Morel, Analysis of the water absorption test to assess the intrinsic permeability of earthen materials, Constr. Build. Mater. $199 \quad$ (2019) 154-162. https://doi.org/10.1016/j.conbuildmat.2018.12.014.

[11] C. Feng, H. Janssen, Hygric properties of porous building materials (III): Impact factors and data processing methods of the capillary absorption test, Build. Environ. $134 \quad$ (2018) 21-34. https://doi.org/10.1016/j.buildenv.2018.02.038.

[12] M. Hall, Y. Djerbib, Moisture ingress in rammed earth: Part 3 - Sorptivity, surface receptiveness and surface inflow velocity, Constr. Build. Mater. $20 \quad$ (2006) 384-395. https://doi.org/10.1016/j.conbuildmat.2005.02.004.

[13] M. Hall, Y. Djerbib, Moisture ingress in rammed earth: Part 2 - The effect of soil particle-size distribution on the absorption of static pressure-driven water, Constr. Build. Mater. 20 (2006) 374-383. https://doi.org/10.1016/j.conbuildmat.2005.01.035.

[14] M. I. Gomes, P. Faria, T. D. Gonçalves, Rammed earth walls repair by earth-based mortars: The adequacy to assess effectiveness, Constr. Build. Mater. $205 \quad$ (2019) $213-231$. https://doi.org/10.1016/j.conbuildmat.2019.01.222.

[15] P. Gerard, M. Mahdad, A. Robert McCormack, B. François, A unified failure criterion for unstabilized rammed earth materials upon varying relative humidity conditions, Constr. Build. Mater. 95 (2015) $437-447$. https://doi.org/10.1016/j.conbuildmat.2015.07.100.

[16] Q. B. Bui, J. C. Morel, S. Hans, P. Walker, Effect of moisture content on the mechanical characteristics of rammed earth, Constr. Build. Mater. 54 (2014) 163-169. https://doi.org/10.1016/j.conbuildmat.2013.12.067.

[17] J. Berger, S. Guernouti, M. Woloszyn, C. Buhe, Factors governing the development of moisture disorders for integration into building performance simulation, J. Build. Eng. 3 (2015) 1-15. https://doi.org/10.1016/j.jobe.2015.04.008.

[18] J. C. Morel, Weathering and durability of earthen material and structures, in: M. R. Hall, R. Lindsay, M. Krayenhoff (Eds.), Modern earth buildings. Materials, engineering, construction and applications, Woodhead Publishing, 2012, pp. 282-303. https://doi.org/10.1533/9780857096166.2.282.

[19] A. Cuccurullo, D. Gallipoli, A. W. Bruno, C. Augarde, P. Hughes, C. La Borderie, Influence of particle grading on the hygromechanical properties of hypercompacted earth, J. Build. Rehabil. 5 (2020) 1-9. https://doi.org/10.1007/s41024-019-0066-4.

[20] M. Hall, The mechanisms of moisture ingress \& migration in rammed earth walls, Sheffield Hallam University (2004).

[21] G. Minke, Earth construction handbook: the building material earth in modern architecture, WIT Press, UK, 2000.

[22] W. Ehlers, Measurement and calculation of hydraulic conductivity in horizons of tilled and untilled loessderived soil, Germany, Geoderma 19 (1977) 293-306. https://doi.org/10.1016/0016-7061(77)90071-4.

[23] M. Sánchez, A. Gens, M. V. Villar, S. Olivella, Fully coupled thermo-hydro-mechanical double-porosity formulation for unsaturated soils, Int. J. Geomech. $16 \quad$ (2016) D4016015-1. https://doi.org/10.1061/(ASCE)GM.1943-5622.0000728.

[24] F. Meng, P. Baud, H. Ge, T. Wong, The effect of stress on limestone permeability and effective stress 
behavior of damaged samples, J. Geophys. Res.: Solid Earth 124 (2019) 376-399. https://doi.org/10.1029/2018JB016526.

[25] S. Rouchier, H. Janssen, C. Rode, M. Woloszyn, G. Foray, J. J. Roux, Characterization of fracture patterns and hygric properties for moisture flow modelling in cracked concrete, Constr. Build. Mater. 34 (2012) 54-62. https://doi.org/10.1016/j.conbuildmat.2012.02.047.

[26] S. Rouchier, Hygrothermal performance assessment of damaged building materials, Université Claude Bernard - Lyon I (2012).

[27] T. Wangler, E. Ngo, G. W. Scherer, Swelling pressure and stress development in clay-bearing sandstones, Proc. 12th Int. Cong. Deterioration and Conservation of Stone (2012).

[28] T. Wangler, Swelling clay and its inhibition in the Villarlod molasse, Proc. 13th Int. Cong. Deterioration and Conservation of Stone 1 (2016) 189-196.

[29] P. Moonen, T. Wangler, An analytical approach to the characterization of swelling in clay-bearing stone, Phil. Mag. 95 (2015) 3103-3121. https://doi.org/10.1080/14786435.2015.1063788.

[30] S. Roels, P. Moonen, K. De Proft, J. Carmeliet, A coupled discrete-continuum approach to simulate moisture effects on damage processes in porous materials, Comput. Methods Appl. Mech. Eng. 195 (2006) 7139-7153. https://doi.org/10.1016/j.cma.2005.05.051.

[31] W. Ehlers, T. Graf, M. Ammann, Deformation and localization analysis of partially saturated soil, Comput. Methods Appl. Mech. Eng. 193 (2004) 2885-2910. https://doi.org/10.1016/j.cma.2003.09.026.

[32] S. Rouchier, M. Woloszyn, G. Foray, J. J. Roux, Influence of concrete fracture on the rain infiltration and thermal performance of building facades, Int. J. Heat Mass Transf. 61 (2013) 340-352. https://doi.org/10.1016/j.ijheatmasstransfer.2013.02.013.

[33] R. El Nabouch, Mechanical behavior of rammed earth walls under pushover tests, Université Grenoble Alpes \& Université Savoie Mont Blanc (2017).

[34] S. Roels, J. Elsene, J. Carmeliet, H. Hens, Characterisation of pore structure by combining mercury porosimetry and micrography, Mater. Struct. 34 (2001) 76-82. https://doi.org/10.1007/BF02481555.

[35] M. R. Hall, S. J. Mooney, C. Sturrock, P. Matelloni, S. P. Rigby, An approach to characterisation of multiscale pore geometry and correlation with moisture storage and transport coefficients in cement-stabilised soils, Acta Geotech. 8 (2013) 67-79. https://doi.org/10.1007/s11440-012-0178-3.

[36] J. Carmeliet, S. Roels, Determination of the isothermal moisture transport properties of porous building materials, J. Therm. Envelope Build. Sci. 24 (2001) 183-210. https://doi.org/10.1106/Y6T2-9LLP-04Y5-AN6T.

[37] M. L. Indekeu, The impact of interior insulation on the hygrothermal performance of rammed earth walls, Université Grenoble Alpes \& Université Savoie Mont Blanc (2021 - in progress).

[38] A. N. Narayanaswamy, Mechanical testing procedure for local building materials: rammed earth and laterite building stones, Ecole nationale des travaux publics de l'Etat (2016).

[39] A. Arrigoni, A. C. Grillet, R. Pelosato, G. Dotelli, C. T. S. Beckett, M. Woloszyn, D. Ciancio, Reduction of rammed earth's hygroscopic performance under stabilisation: an experimental investigation, Build. Environ. 115 (2017) 358-367. https://doi.org/10.1016/j.buildenv.2017.01.034.

[40] C. Feng, H. Janssen, Y. Feng, Q. Meng, Hygric properties of porous building materials: Analysis of measurement repeatability and reproducibility, Build. Environ. $85 \quad$ (2015) 160-172. https://doi.org/10.1016/j.buildenv.2014.11.036. 
[41] C. H. Kouakou, J. C. Morel, Strength and elasto-plastic properties of non-industrial building materials manufactured with clay as a natural binder, Appl. Clay Sci. $44 \quad(2009)$ 27-34. https://doi.org/10.1016/j.clay.2008.12.019.

[42] G. W. Scherer, Internal stress and cracking in stone and masonry, in: M. S. Konsta-Gdoutos (Ed.), Measuring, Monitoring and Modeling Concrete Properties, Springer, Dordrecht, 2006, pp. 633-641. https://doi.org/10.1007/978-1-4020-5104-3_77.

[43] I. J. Gonzalez, G. W. Scherer, Effect of swelling inhibitors on the swelling and stress relaxation of clay bearing stones, Environ. Geol. 46 (2004) 364-377. https://doi.org/10.1007/s00254-004-1038-8.

[44] R. J. Gummerson, C. Hall, W. D. Hoff, Water movement in porous building materials-II. Hydraulic suction and sorptivity of brick and other masonry materials, Build. Environ. 15 (1980) 101-108. https://doi.org/10.1016/0360-1323(80)90015-3.

[45] C. Feng, H. Janssen, Hygric properties of porous building materials (II): Analysis of temperature influence, Build. Environ. 99 (2016) 107-118. https://doi.org/10.1016/j.buildenv.2016.01.016.

[46] M. A. Wilson, W. D. Hoff, C. Hall, Water movement in porous building materials - XIII. Absorption into a two-layer composite, Build. Environ. 30 (1995) 209-219. https://doi.org/10.1016/0360-1323(94)00035-Q.

[47] M. A. Wilson, W. D. Hoff, C. Hall, Water movement in porous building materials - XIV. Absorption into a two-layer composite $\left(S_{A}<S_{B}\right)$, Build. Environ. 30 (1995) 221-227. https://doi.org/10.1016/03601323(94)00036-R.

[48] M. Indekeu, M. Woloszyn, A. C. Grillet, L. Soudani, A. Fabbri, Towards hygrothermal characterization of rammed earth with small-scale dynamic methods, Energy Proc. 132 (2017) 297-302. https://doi.org/10.1016/j.egypro.2017.09.731.

[49] S. Roels, J. Carmeliet, Analysis of moisture flow in porous materials using microfocus X-ray radiography, Int. J. Heat Mass Transf. 49 (2006) 4762-4772. https://doi.org/10.1016/j.ijheatmasstransfer.2006.06.035.

[50] B. J. Pease, G. A. Scheffler, H. Janssen, Monitoring moisture movements in building materials using X-ray attenuation: Influence of beam-hardening of polychromatic X-ray photon beams, Constr. Build. Mater. 36 (2012) 419-429. https://doi.org/10.1016/j.conbuildmat.2012.04.126.

[51] E. Vereecken, Hygrothermal analysis of interior insulation, KU Leuven (2013).

[52] M. I. Gomes, T. D. Gonçalves, P. Faria, Hydric behavior of earth materials and the effects of their stabilization with cement or lime: study on repair mortars for historical rammed earth structures, J. Mater. Civ. Eng. 28 (2016) 04016041. https://doi.org/10.1061/(ASCE)MT.1943-5533.0001536.

[53] J. Carmeliet, Duurzaamheid van weefselgewapende pleisters voor buitenisolatie. Een probabilistische benadering op basis van de niet-lokale continue schademechanica, KU Leuven (1992).

[54] J. Carmeliet, Multischaal bouwfysica : van porie tot macroklimaat, Technische Universiteit Eindhoven, Eindhoven, 2003. 